\title{
Bone metastases diagnosis possibilities in studies with the use of ${ }^{18} \mathrm{~F}-\mathrm{NaF}$
} and ${ }^{18 F-F D G}$

Małgorzata Tarnawska-Pierścińska1', Łukasz Hołody ${ }^{1}$, Janusz Braziewicz ${ }^{2}$, Leszek Królicki ${ }^{3}$

1'Department of Nuclear Medicine, Holycross Cancer Centre, Kielce, Poland ${ }^{2}$ The Jan Kochanowski University of Humanities and Sciences, Kielce, Poland

${ }^{3}$ Medical University of Warsaw, Poland

\section{[Received 29 VIII 2011; Accepted 16 XI 2011]}

\begin{abstract}
Scintigraphy of the skeletal system is performed mainly with the use of ${ }^{99 \mathrm{~m} T c-M D P}$. There are other radiopharmaceuticals showing affinity to bone lesions: ${ }^{99 m} \mathrm{TC}-\mathrm{MIBG},{ }^{201} \mathrm{TI},{ }^{131} \mathrm{I}$ (in the case of papillary or follicular thyroid cancers), and ${ }^{99 m} \mathrm{mc}$ (V) DMSA (in the case of medullary cancer). Currently, positron emitted radioisotopes are also used in clinical practice. It seems that ${ }^{18} \mathrm{~F}-\mathrm{NaF} / \mathrm{PET}$ is a highly sensitive and specific modality for detection of metastases and other bone lesions. Certain data concerning the role of ${ }^{18} \mathrm{~F}$-FDG, ${ }^{18} \mathrm{~F}$-choline, or ${ }^{68} \mathrm{Ga}$-DOTATATE can be found. The aim of this article is to review the role of ${ }^{18} \mathrm{~F}-\mathrm{NaF}$ and ${ }^{18} \mathrm{~F}-\mathrm{FDG}$ in diagnosis of bone metastases.

Key words: sodium fluoride ${ }^{18} \mathrm{~F}-\mathrm{NaF}$, fluorodeoxyglucose ${ }^{18} \mathrm{~F}-\mathrm{FDG}$, methylene diphosphonate ${ }^{99 \mathrm{~m} T C-M D P}$, Bone metastases, lung cancer, breast cancer, prostate cancer
\end{abstract}

Nuclear Med Rev 2011; 14, 2: 105-108

Correspondence to: Małgorzata Tarnawska-Pierścińska

Zakład Medycyny Nuklearnej z ośrodkiem PET

Świętokrzyskie Centrum Onkologii

ul. S. Artwińskiego 3, 25-734 Kielce

tel: 4136748 81, fax: 413674887

e-mail: m_tarnawska@interia.pl

\section{Introduction}

The number of patients suffering from neoplasm in Europe amounts to over 3 million people, while mortality reaches 1.7 million people a year. Neoplastic metastases to the skeletal system occur in $50 \%$ of oncologic patients. In $70 \%$ of cases they are connected with the presence of breast and prostate cancer. The presented epidemiologic data indicate the clinical importance of diagnosing metastatic foci to the skeletal system.

Evaluation of disease stage prior to prescribing treatment plays a fundamental role in oncologic disease as it allows an optimal therapy scheme to be chosen. It involves imaging diagnostics of the skeletal system. Due to limitations in diagnostic methods, clear evaluation of lesions within the skeletal system still remains a clinical issue.

The presence of metastatic foci depends on two basic phenomena: angiogenesis and neoplastic cells producing adhesion factors that allow the cells to develop outside primary tumour site. The presence of activated osteoclasts, osteoblasts, inflammatory cells, and neoplastic cells is observed in metastatic focus. Multidirectional interactions can be noticed between these components. The majority of neoplastic cells show an ability to produce and release numerous factors that promote osteoclast multiplication, differentiation, and activation.

\section{Radiology tests}

Metastatic lesions in the bone in the initial phase infiltrate bone marrow, then surround the bone and thus disturb the balance enhancing osteolytic or osteoblastic processes. Radiologic evaluation distinguishes three types of metastatic lesion to bone: lytic, sclerotic, and mixed. Fast-development and aggressive metastases usually have a lytic nature, while slow-development metastases are typically accompanied by osteoblastic processes. The latter observed within the bone might also indicate regeneration processes. Lytic lesions mainly accompany metastases of the urinary bladder, kidney, and thyroid cancer as well as melanoma. Osteoblastic lesions typically develop in the case of cancer of: prostate, mammary gland, 
sometimes lungs, stomach, pancreas, head, and neck and rarely large intestine [1].

Metastatic foci are visible in computer tomography when bone density decreases by $30-75 \%$. In the initial stage of the disease, the method is not recommended in the initial diagnostics of skeletal system metastases due to limited sensitivity.

Magnetic Resonance Imaging allows for evaluation of neoplastic lesions within bone marrow due to high sensitivity. However, the specificity of this method is moderate (differentiation of active proliferative lesions with scars, necrosis, angioma, or fracture) MRI fails to provide evaluation of bone structures, which is critical for diagnosis in a number of cases (calcified structures do not emit MRI signal).

Another limitation to radiology methods (X-rays, CT, MRI) is the scope of the tests - they typically involve a particular part of the body. Radioisotope techniques allow for a precise evaluation of the whole skeleton. Due to the functional character of radioisotope techniques the tests are more sensitive: metastatic foci are visible in the case of a-few-percent decalcification. Therefore, radioisotope tests are currently considered as the "gold standard" in the evaluation of oncologic disease stage. It seems that whole body MRI with the use of diffusion sequences will play a similar role.

\section{Scintigraphic test with the use of ${ }^{99 m T c-M D P}$}

Bone scintigraphy with the use of 99mTc-MDP allows for detection of foci of improper radiopharmaceutical accumulation at an early stage of the disease when decalcification amounts only to $5-10 \%$ compared to healthy bone tissue. Thus, in scintigraphic studies the lesions are visible $2-18$ months earlier than in radiology tests [1].

The accumulation mechanism of 99mTc-MDP has not been fully understood so far. Neither a relation between osteoblast number and the substance accumulation level nor tracer accumulation in collagen have been observed in clinical trials. This suggests that ${ }^{99 m}$ Tc-MDP accumulates in bone tissue as a result of chemical absorption and incorporation into the hydroxyapatite structure. This accumulation depends on the type of the disease and micro-environmental conditions such as $\mathrm{pH}$ and phosphate concentration. The described ${ }^{99 m} \mathrm{Tc}-\mathrm{MDP}$ accumulation mechanisms explain certain method limitations, among others lower test sensitivity in diagnostics of metastases with domination of osteolytic lesions and lower osteoblast activity or osteolytic metastases with fast bone damage [1]. Lytic lesions are visible in scintigraphic studies as "cold" areas that are difficult to interpret. The clinical importance of this method is presented in the article by $M$. Bączyk published in this journal issue.

\section{PET}

The first radiopharmaceutical used for imaging skeletal lesions was sodium fluoride ( $\left.{ }^{18} \mathrm{~F}-\mathrm{NaF}\right)$, introduced in the sixties. In the seventies phosphonate labelled derivatives were introduced into scintigraphy [2]. Their sensitivity, diagnostic effectiveness, and cost appeared to be so attractive that studies with the use of ${ }^{18} \mathrm{~F}-\mathrm{NaF}$ became considerably limited. However, currently, due to PET-CT development, an increasing interest in this radiopharmaceutical can be observed [3]. The second frequently used radiopharmaceutical in bone metastases diagnostics is ${ }^{18} \mathrm{FDG}$. In many cases the studies that use both tracers are complementary.

\section{${ }^{18} \mathrm{~F}-\mathrm{NaF}$}

This radiopharmaceutical was first used by Blau et al. [4] in 1962. Considerably better PET resolution and ${ }^{18} \mathrm{~F}-\mathrm{NaF}$ pharmacokinetic properties make it a great tracer in evaluation of bone metastases [5] and lesions in the course of trauma and metabolic diseases. This radiopharmaceutical was registered by the FDA as a safe and effective drug in diagnostics of skeletal diseases. The ${ }^{18} \mathrm{~F}$ dose applied in diagnostic studies is less than $8.4 \mu \mathrm{g} / \mathrm{kg}$. Therefore, no pharmacodynamic effect of the radiopharmaceutical is observed. Data on toxicity, genotoxicity, or cancerogenesis are not known as the preparation dose used in the study is trace and typically administered only once. No studies connected with the radiopharmaceutical effect on the foetus have been carried out. However, the rules of patient radiology protection should be the same as in the case of other radioactive preparations.

No data on radiopharmaceutical content in breast milk of nursing mothers can be found. Thus, breastfeeding ought to be stopped. The safety of the ${ }^{18} \mathrm{~F}-\mathrm{NaF}$ effect on children has not been determined. Thus, the study on this group of patients can be conducted following a profound analysis of risks and benefits (similarly to other pharmaceuticals from this group, particularly the intense accumulation of ${ }^{18} \mathrm{~F}-\mathrm{NaF}$ which takes place within epiphyseal cartilage). The dose of absorbed radiation for particular organs is between $0.0028 \mathrm{mGy} / \mathrm{MBq}$ (for mammary glands), 0.028, and 0.019 mGy/MBq (for bone marrow and kidneys, respectively). As regards the wall of the urinary bladder, it amounts to $0.25 \mathrm{mGy} / \mathrm{MBq}$ (FDA, 2000).

No pharmaceutical interactions with other medicines are known The studies on chemical purity indicate that basic chemical substances present in pharmaceutical solution are silver salts. They have trace concentration of maximum $0.3 \mathrm{ug} / \mathrm{ml}$. Also, radiochemical purity in reference to radioisotopes of half-life over 2 hours was examined. Their content is within background limits. No significant risk connected with their presence has been observed.

The pharmacokinetics of ${ }^{18} \mathrm{~F}-\mathrm{NaF}$ were recently described by Modlin et al. [6]. Accumulation level of ${ }^{18} \mathrm{~F}-\mathrm{NaF}$ in the skeletal system depends most of all on blood flow. Almost all fluorides accumulate in bone tissue as early as during the first passing. Accumulation within bone marrow is scarce.

The accumulation mechanism of ${ }^{18} \mathrm{~F}-\mathrm{NaF}$ involves fast chemisorption on hydroxyapatite crystals. Next, they are exchanged with hydroxyl groups, which leads to formation of fluoroapatite. The process of fluoride incorporation into bone matrix might last for as long as many weeks and depends on osteoblastic and osteolytic process intensity. Fluorides accumulate mainly in the surface layer of the bone (within which "remodelling" processes are the most intense). Thus, the fluoride accumulation level depends on blood flow but also on the surface of the bone structure, which is considerably greater in disease foci in the case of both benign and malignant disease. It should be emphasized that the surface of the bone layer in a sample weighing $1 \mathrm{gram}$ amounts to $300 \mathrm{~m}^{2}$. Accumulation of ${ }^{18} \mathrm{~F}-\mathrm{NaF}$ within metastases is $3-10$ times greater compared to healthy bone tissue.

Contrary to 99mTc-MDP, the pharmaceutical does not connect with plasma protein and thus is quickly excreted from kidneys to 
urine. Also, pharmaceutical affinity to cell membranes or other cell structures has not been observed. Radioactivity in red blood cells is two times lower than in the plasma and amounts to approximately $30 \%$ of the administered dose. Since fluoride exchange between intra- and extracellular space is based on free diffusion, it has no significant impact on the quality of the obtained scintigraphy images (on the degree of background radiation). Therefore, the test might be performed considerably earlier than in the case of 99mTc-MDP application. Two hours after intravenous administration of ${ }^{18} \mathrm{~F}-\mathrm{FDG}$ to the patient with normal kidney function approximately $50 \%$ of the pharmaceutical accumulates in the skeletal system, while over $20 \%$ of the dose is excreted with urine [5]. One hour after administration blood plasma shows only $10 \%$ of total radioactivity. Renal clearance for ${ }^{18} \mathrm{~F}-\mathrm{NaF}$ is similar to the GFR value $(70-90 \%$ of GFR value). The level of pharmaceutical excretion with urine depends on diuresis value and urine $\mathrm{pH}$. The dependency on $\mathrm{pH}$ indicates that the fluoride is reabsorbed in renal tubules (in the form of hydrogen fluoride). Increased diuresis reduces radiopharmaceutical reabsorption. Therefore, proper hydration of the patients before and after ${ }^{18} \mathrm{~F}-\mathrm{NaF}$ administration is particularly important. Thiazides increase ${ }^{18} \mathrm{~F}$ excretion and decrease its urine concentration (due to diuresis increase).

The greatest radiopharmaceutical accumulation takes place between the $45^{\text {th }}$ and $90^{\text {th }}$ minutes after administration. The test is performed every 60 minutes after intravenous administration of 250-450 MBq (8-12 mCi) of ${ }^{18} \mathrm{~F}-\mathrm{NaF}$. Typically, the acquisition/bed time amounts to $2-5$ minutes [5]. The test should include the whole body: from the top of the skull to the feet (in certain centres - to $1 / 2$ of femoral bones).

${ }^{18} \mathrm{~F}-\mathrm{NaF}$ accumulates in all the areas of the skeletal system, particularly within the spine and pelvis and also in periarticular areas.

Increased accumulation of the tracer in metastases foci is observed in the case of both osteoblastic and osteolytic lesions (each osteolytic lesion is even accompanied by low osteoblastic activity; this can be observed in PET but not always in SPECT). Thus, PET with the use of ${ }^{18} \mathrm{~F}-\mathrm{NaF}$ is more sensitive compared to scintigraphy with the use of ${ }^{99 m} \mathrm{Tc}-\mathrm{MDP}$.

Similarly to ${ }^{99 \mathrm{~m} T c-M D P},{ }^{18} \mathrm{~F}-\mathrm{NaF}$ also accumulates in benign lesions, which is a limitation to the method in oncologic diagnostics. Increased ${ }^{18} \mathrm{~F}-\mathrm{NaF}$ accumulation is observed in inflammations, past trauma, fibrous dysplasia, Paget's disease, hyperostosis frontalis, and myositis ossificans [5, 6]. Differentiation of these lesions with metastatic foci based on tracer uptake (SUV) is impossible, which considerably impedes test result interpretation.

${ }^{18} \mathrm{~F}-\mathrm{NaF}$ test is not applied in routine diagnostics of bone metastases due to limited availability and cost. Indications for ${ }^{18} \mathrm{~F}-\mathrm{NaF}$ test are as follows: high risk of tumour dissemination to bone despite normal or unclear ${ }^{99 \mathrm{~m} T c-M D P}$ scintigraphy picture and diagnosis of neoplastic disease with osteolytic bone metastases [7-9]. It is currently assumed that diagnosis of lung, mammary gland, and prostate cancer are basic indications for the test with the use of ${ }^{18} \mathrm{~F}-\mathrm{NaF}$ [7]

Schirrmeister et al. [10] compared PET diagnostic effectiveness following ${ }^{18} \mathrm{~F}-\mathrm{NaF}$ administration to a scintigraphic test following ${ }^{99 m} \mathrm{Tc}-\mathrm{MDP}$ administration in diagnostics of bone metastases of various lytic tumours. Additionally, CT, MRI, and scintigraphy were performed following administration of 131I. The examined group included 44 patients with cancer of prostate, lung, or thyroid. The
${ }^{18} \mathrm{~F}-\mathrm{NaF}$ test revealed 96 metastatic lesions in 15 individuals, while ${ }^{99 m} \mathrm{Tc}-\mathrm{MDP}$ revealed only 46 . The ${ }^{18} \mathrm{~F}-\mathrm{NaF}$ study revealed all the lesions observed in the ${ }^{99 m} \mathrm{~m}$ C-MDP study. The differences between the studies referred mainly to metastatic lesions within the spine. Scintigraphy with the use of ${ }^{99 \mathrm{~m} T c-M D P}$ showed the presence of $40 \%$ of metastatic lesions in this area. PET sensitivity amounted to $91.6 \%$, while scintigraphy amounted to $41.7 \%$ in diagnosing metastatic lesions of both osteolytic and osteoblastic nature.

Bury et al. [11] compared the sensitivity and specificity of

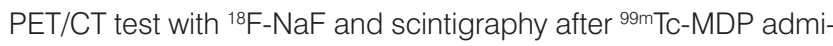
nistration in 110 patients. The sensitivity of both PET and classic scintigraphy amounted to $90 \%$, while specificity was $98 \%$ and $61 \%$, respectively.

Even-Sapir et al. [1] compared studies with the use of ${ }^{99 m} T c-M D P$ (WB, SPECT) as well as with the use of ${ }^{99 m} T c-M D P$ performed on 44 patients with prostatic cancer and high risk of bone metastases. Sensitivity, specificity, positive predictive value (PPV), and negative predictive value (NPV) were as follows: for WB $-70 \%, 57 \%, 64 \%$ and $55 \%$, respectively, for SPECT - 92\%,82\%, 86\%, and 90\%, respectively, for PET - 100\%, 62\%, $74 \%$, and $100 \%$, respectively, while in the case of PET/CT all the parameters amounted to $100 \%$.

In 2010 the institutions responsible for recording the clinical effectiveness of medical procedures according to based evidence medicine (Medicare, CMS) commenced a program evaluating skeletal system scintigraphy with the use of ${ }^{18} \mathrm{~F}-\mathrm{NaF}$. The study has prospective character and is aimed at answering the following question: Does the result of ${ }^{18} \mathrm{~F}-\mathrm{NaF}$ scintigraphy allow the choice of a more suitable treatment or palliative therapy which would lead to improvement of life quality or lengthening life? According to internet data (February 2011) of the American Board of Nuclear Medicine, the National Cancer Institute handed the Food and Drug Administration a recommendation of ${ }^{18} \mathrm{~F}-\mathrm{NaF}$ registration as an alternative to ${ }^{99 m} \mathrm{TC}-\mathrm{MDP}$ pharmaceutical for skeletal system studies. The Institute stated that an increase in ${ }^{18} \mathrm{~F}-\mathrm{NaF}$ availability would hopefully reduce the cost of the study. It should be emphasized that the first ${ }^{18} \mathrm{~F}-\mathrm{NaF}$ registration by the FDA was performed in 1972. In 1975 commercial production of ${ }^{18} \mathrm{~F}-\mathrm{NaF}$ was stopped. In 2000 the FDA again issued an opinion on the usefulness and safety of this pharmaceutical.

\section{${ }^{18} \mathrm{~F}-\mathrm{FDG}$}

${ }^{18} \mathrm{~F}-\mathrm{FDG}$ is the most commonly used tracer in diagnostics of neoplastic disease with the use of PET technique. Contrary to ${ }^{18} \mathrm{~F}-\mathrm{NaF}$, this radiopharmaceutical is not bone specific. However, it should be emphasized that compared to other diagnostic methods, ${ }^{18} \mathrm{~F}-\mathrm{FDG}$ has a great property which allows for direct imaging of metastatic lesions (the radiopharmaceutical accumulates in neoplastic cells, while other methods allow determination of indirect signs of the disease). ${ }^{18} \mathrm{~F}-\mathrm{FDG}$ is transported to cells by transport protein present in the Glut cellular membrane. A considerably higher Glut 1 protein expression is observed in neoplastic cells. The protein transports glucose to the cell without insulin participation. The process of phosphorylation takes place in the cell.

In normal bone marrow low glucose metabolism can be typically observed and thus accumulation of ${ }^{18} \mathrm{~F}-\mathrm{FDG}$ is also low. Increased glucose metabolism also occurs in early stage of metastasis, during bone marrow infiltrate before any visible reaction 
of bone tissue. Therefore, the foci diagnosed following ${ }^{18} \mathrm{~F}-\mathrm{FDG}$ administration might not be visible in CT and scintigraphy.

The sensitivity of ${ }^{18} \mathrm{~F}$-FDG PET in detecting bone metastases amounts to $62-100 \%$ while specificity amounts to $96-100 \%$ [1]. PET with ${ }^{18} \mathrm{~F}-\mathrm{FDG}$ allows for diagnosis of skeletal metastases of various natures: osteolytic, osteosclerotic, and mixed. However, it is more sensitive in detecting osteolytic lesions rather than osteosclerotic in coomparison to methods with the use of other radiopharmaceuticals. Metser et al. [12] observed increased ${ }^{18} \mathrm{~F}-\mathrm{FDG}$ accumulation in $100 \%$ of the lesions described as lytic in $\mathrm{CT}$ and in $88 \%$ of the lesions described as sclerotic. Current observations indicate that test sensitivity in metastatic foci diagnostics is at least comparable to scintigraphy with the use of ${ }^{18} \mathrm{~F}-\mathrm{FDG}$. However, a number of reports suggest that sensitivity of ${ }^{18} \mathrm{~F}-\mathrm{FDG}-\mathrm{PET}$ is lower than in scintigraphy with the use of 99mTc-MDP in mammary gland cancer. Similarly, this radiopharmaceutical is less useful in diagnostics of prostatic cancer. However, in evaluation of lymphoma metastatic foci this method has a higher sensitivity

\section{Conclusions}

Studies on the skeletal system with the use of PET/CT are used in clinical practice more and more often. In particular, the role of ${ }^{18} \mathrm{~F}-\mathrm{NaF}$ is emphasized. In recent years, a number of scientific institutions have commenced regular prospective studies regarding the usefulness of this radiopharmaceutical. It is stressed that the use of ${ }^{18} \mathrm{~F}-\mathrm{NaF}$ allows:

- the earliest identification of skeletal metastatic lesions;

- precise determination of neoplastic disease stage (in reference to skeletal system involvement);

- determination of biopsy site, if necessary for final diagnosis;

- monitoring response to the treatment. Values of this technique include:

- two-fold greater tracer accumulation in skeletal system compared with ${ }^{99 m} \mathrm{Tc}-\mathrm{MDP}$;

- considerably quicker ${ }^{18} \mathrm{~F}-\mathrm{NaF}$ excretion from blood (due to lack of affinity to blood proteins);
— high value of bone tissue/background coefficient;

— shorter test duration;

- easy patient preparation for the test; no limitations to diet of physical activity are required;

- possibility of conducting the test regardless of glucose concentration in the blood.

\section{References}

1. Even Sapir E. Imaging of malignant bone involvement by morphologic, scintigraphic, and hybrid modalities. J Nucl Med 2005; 46: 1356-1367.

2. Królicki L. Medycyna nuklearna. Warszawa 1996.

3. Grant FD. Skeletal PET with 18F-fluoride: applying new technology to an old tracer. J Nucl Med 2008; 49: 68-78.

4. Blau M, Nagler W, Bender M. Fluorine-18: a new isotope for bone scanning. J Nucl Med 1962; 3: 332-334.

5. Cook GJR. The role of position emission tomography in the management of bone metastases. Cancer 2000; 88 (suppl): 2927-2933.

6. Czernin J, Satyamurthy N, Schiepers Ch. Molecular mechanisms of bone ${ }^{18} \mathrm{~F}-\mathrm{NaF}$ deposition. J Nucl Med 2010; 51: 1826-1829.

7. Even Shapir E, Metser U, Mishani E et al. The detection of bone metastases in patients with high-risk prostate cancer: ${ }^{99 m} \mathrm{TC}-\mathrm{MDP}$ planar bone scintigraphy, single- and multi-field-of-view SPECT, ${ }^{18}$ F-fluoride PET, and ${ }^{18}$ F-fluoride PET/CT J Nucl Med 2006; 47: 287-297.

8. Sodium Fluoride F18 injection investigator's brochure - Cancer Imaging Program Division of Cancer Treatment and Diagnosis National Institutes of Health 6130 Executive Blvd. Edition 1, August 2008.

9. Joo-Won Min. The role of whole-body FDG PET/CT, ${ }^{99 m}$ Tc-MDP bone scintigraphy, and serum alkaline phosphatase in detecting bone metastasis in patients with newly diagnosed lung cancer. J Korean Med Sci 2009; 24: 275-280.

10. Schirrmeister $H$, Guhlmann A, Elsner $K$ et al. Sensitivity in detecting osseous lesions depends on anatomic localization: planar bone scintigraphy versus ${ }^{18} \mathrm{~F}$ PET. J Nucl Med 1999; 40: 1623-1629.

11. Bury $T$, Barreto $A$, Daenen $F$ et al. Fluorine-18 deoxyglucose positron emission tomography for the detection of bone metastases in patients with non-small cell lung cancer. Eur J Nucl Med 1998; 25: 1244-1247.

12. Metser $\mathrm{U}$, Lerman $\mathrm{H}$, Blank $\mathrm{A}$ et al. Malignant involvement of the spine: assessment by 18F-fluorodeoxyglucose PET/CT. J Nucl Med 2004; 45: 279-284. 